\title{
Hubungan pemberian imunisasi BCG dengan kejadian TB paru pada anak di Puskesmas Tuminting periode Januari 2012 - Juni 2012
}

\author{
Christian K. Susanto \\ Audrey Wahani \\ Johnny Rompis
}

\author{
${ }^{1}$ Kandidat Skripsi Fakultas Kedokteran Universitas Sam Ratulangi Manado \\ ${ }^{2}$ Bagian Ilmu Kesehatan Anak Fakultas Kedokteran Universitas Sam Ratulangi Manado \\ Email: christian92_inside@yahoo.com
}

\begin{abstract}
Pulmonary Tuberculosis (Tb) is still a public health problem. The prevalence of pulmonary $\mathrm{Tb}$ from year to year in Manado is still high even though the management of strategy is relatively the same- prevention by immunization, case finding, and treatment strategy with supervision and with DOT directly. Prevention with immunization results in better body resistance. Immunization against $\mathrm{Tb}$ is required in some countries and is recommended in several other countries. Although the majority of toddlers are already BCG vaccinated there are still many pulmonary Tb cases among children in Manado. This study aimed to obtain the relationship between the BCG immunization and pulmonary TB occurence in children in Tuminting Primary Health Care, Manado. The results showed that at Tuminting Primary Health Care most of the toddlers had been BCG immunized. Tuberculosis was found among toddlers aged $>3$ years and there was a significant correlation between BCG immunization and the occurence of tuberculosis with an OR 0.804 .
\end{abstract}

Keywords: immunization BCG, occurence of TB

\begin{abstract}
Abstrak: Penyakit TB paru sampai saat ini masih menjadi masalah kesehatan masyarakat. Prevalensi TB paru dari tahun ke tahun di Kota Manado tetap tinggi meskipun strategi penanganan yang diterapkan relative sama, yaitu pencegahan dengan imunisasi. penemuan penderita, dan pengobatan dengan strategi DOT atau dengan pengawasan minum obat secara langsung. Pencegahan dengan imunisasi merupakan tindakan yang mengakibatkan seseorang mempunyai ketahanan tubuh yang lebih baik. Imunisasi terhadap penyakit TB telah diwajibkan di beberapa negara serta direkomendasikan di beberapa negara lainnya. Penyakit TB banyak terjadi pada anak di Kota Manado padahal anak balita tersebut sebagian besar sudah divaksinasi BCG. Penelitian ini bertujuan untuk mengetahui hubungan antara pemberian imunisasi BCG dengan kejadian TB Paru pada anak di Puskesmas Tuminting Manado. Hasil penelitian memperlihatkan bahwa sebagian besar anak balita yang berobat di Puskesmas Tuminting telah diberikan imunisasi BCG. Kejadian tuberkulosis ditemukan pada umur $>3$ tahun dan terdapat hubungan bermakna antara pemberian imunisasi BCG dengan kejadian tuberkulosis paru dengan nilai OR 0,804.
\end{abstract}

Kata kunci: imunisasi BCG, kejadian TB paru

Tuberkulosis pada anak mencapai 15\%$40 \%$ dari setiap kasus TB. ${ }^{1-5}$ Angka penularan yang tinggi pada daerah endemik TB disebabkan oleh densitas kasus yang tinggi dan tingginya keterlambatan diagnostik. $^{2}$ Karena TB pada anak menggambarkan adanya penularan yang terus berlangsung, anak sering terkena TB pada daerah dimana epidemik orang dewasa sulit dikontrol. ${ }^{3}$ TB pada anak masih sering diabaikan karena berbagai alasan, seperti kesulitan mendiagnosis TB 
pulmonal, kurangnya penelitian ilmiah mengenai TB anak, banyak yang tidak diketahui mengenai akibat terhadap anak dengan TB dan kepercayaan bahwa TB pada anak bukan merupakan faktor penting dalam mengontrol TB. ${ }^{6}$

Di negara-negara maju seperti Eropa dan Amerika Serikat, Tuberkulosis paru boleh dikatakan relatif mulai langka. Dalam urutan penyakit-penyakit yang disusun menurut frekuensi, baik morbiditas maupun mortalitas, tuberkulosis paru menduduki tempat yang jauh lebih rendah dibanding penyakit-penyakit seperti kanker dan kelainan-kelainan kardiovaskular. Hal ini adalah berkat tingginya standar hidup (kondisi perumahan, gizi, dan sebagainya) dan kemajuan-kemajuan dalam cara pengobatan. $^{6,7}$

Di Indonesia faktor-faktor tersebut diatas masih banyak memerlukan perbaikan dan frekuensi penyakit tuberkulosis paru masih cukup tinggi. Hasil penelitian FKUI pada tahun tujuh puluhan terhadap ribuan buruh perusahaan, pegawai kantor, mahasiswa dan pelajar, yang menjalani pemeriksaan roentgen (check-up) secara massal menunjukkan angka yang masih cukup tinggi, yaitu sekitar 3\% ditemui adanya kelainan yang didiagnosis sebagai proses spesifik (tuberkulosis). Penelitian yang dilakukan oleh suatu tim dari WHO di daerah Yogyakarta dalam kurun waktu yang sama, dengan disertai pemeriksaan bakteriologik, menunjukkan hasil yang kurang lebih sama. ${ }^{8}$

Menurut WHO, sepertiga dari populasi dunia diperkirakan terinfeksi dengan Mycobacterium Tuberculosis. Pada tahun 2009, terdapat 9,4 juta kasus baru dengan 1,7 juta kematian secara global. Sebagian besar kematian terdapat pada negara berkembang yang memiliki keterbatasan sumber daya. ${ }^{7}$ Di Asia Afrika ditemukan kasus TB Paru 2 kali lebih besar dari Asia Tenggara yaitu 350 per 100.000 penduduk. ${ }^{9}$ Diperkirakan angka kematian akibat TB Paru adalah 8.000 setiap hari dan 2,3 juta setiap bulan. Laporan WHO tahun 2004 menyebutkan bahwa jumlah terbesar kematian akibat TB Paru terdapat di Asia
Tenggara yaitu 625.000 orang. Tiga negara dinyatakan sebagai negara dengan "disease burden” tertinggi, yaitu Cina, India, dan salah satunya ialah Indonesia. ${ }^{7}$

Di Indonesia terdapat 583.000 kasus TB paru, dengan kematian 140.000 dan 13/100.000 penduduk merupakan penderita baru. Prevalensi TB paru pada tahun 2002 mencapai 555.000 kasus (256 kasus/ 100.000 penduduk), dan $46 \%$ diantaranya merupakan kasus baru atau kasus baru meningkat 104/100.000 penduduk.Menurut Survey Kesehatan Rumah Tangga tahun 1995 (SKRT 1995) TB paru merupakan penyebab kematian nomor satu untuk penyakit infeksi di Indonesia. Prevalensi nasional Tuberkulosis Paru (berdasarkan diagnosis tenaga kesehatan dan keluhan responden) menyatakan bahwa prevalensi TB paru klinis 0,99\% dari seluruh penyakit di Indonesia. ${ }^{8}$

WHO melaporkan adanya 3 juta orang mati akibat TB paru setiap tahun dan diperkirakan 5000 orang setiap harinya. Tiap tahun ada 9 juta penderita TB paru baru dari 25\% kasus kematian dan kesakitan. Masyarakat yang menderita TB paru ialah orang-orang pada usia produktif yaitu dari 15-54 tahun. ${ }^{7}$ Prevalensi TB paru 20\% lebih tinggi pada laki-laki disbandingkan perempuan, tiga kali lebih tinggi di pedesaan dibandingkan perkotaan dan empat kali lebih tinggi pada pendidikan rendah dibandingkan pendidikan tinggi. ${ }^{10}$

Di Sulawesi Utara, penderita TB paru pada tahun 2009 yaitu \pm 423 dan meningkat pada tahun 2010 yaitu \pm 466 penderita. Case Detection Rate TB paru di Indonesia per Juni 2012 terdapat sekitar 60,81\% kasus TB paru di Sulawesi Utara dan angka ini menunjukkan kasus tertinggi di seluruh provinsi di Indonesia. ${ }^{11}$

Imunisasi adalah upaya yang dilakukan dengan sengaja memberikan kekebalan (imunitas) pada bayi atau anak sehingga terhindar dari penyakit. Imunisasi juga merupakan upaya pencegahan primer yang sangat efektif untuk menghindari terjangkitnya penyakit infeksi. Dengan demikian, angka kejadian penyakit infeksi akan menurun, kecacatan serta kematian 
yangditimbulkannya pun akan berkurang. ${ }^{12}$

Berdasarkan latar belakang diatas, peneliti tertarik untuk melakukan penelitian hubungan antara pemberian imunisasi Bacillus Calmette Guerin dengan kejadian TB paru pada anak.

\section{METODE PENELITIAN}

Jenis penelitian ini non eksperimental dengan desain studi komparatif yang bersifat Case Control (retrospektif). Penelitian ini bertujuan untuk mengetahui adanya hubungan antara pemberian imunisasi BCG dengan kejadian TB Paru pada anak di Puskesmas Tuminting Manado. Penentuan sampel secara non random sampling (jenis sampling jenuh). Subyek penelitian (responden) ialah semua anak yang sedang menjalani pengobatan di Puskesmas Tuminting Manado. Jumlah sampel sebanyak 56 responden (25 kasus dan 31 kontrol). Pengumpulan data diambil dari rekam medik dan mengisi kuisioner berbentuk pertanyaan tertutup yang diberikan kepada orang tua anak.

\section{HASIL PENELITIAN}

Penelitian ini dilakukan di Puskesmas
Tuminting dengan jumlah responden 56 balita. Penderita tuberkulosis paru pada anak balita yang menjadi subyek penelitian di Puskesmas Tuminting sebagian besar berumur $>3$ tahun (62,5\%) (Tabel 1). Penderita tuberkulosis paru pada anak balita yang menjadi subyek penelitian di Puskesmas Tuminting sebagian besar berjenis kelamin laki-laki (58,92\%) (Tabel 2).

Responden yang menderita tuberkulosis paru sebanyak 25 responden (44,65\%) dan yang tidak menderita tuberkulosis paru sebanyak 31 responden (55,35\%) (Tabel 3).

Analisis bivariat dengan melihat nilai rasio Odds (OR) dengan interval kepercayaan (CI) 95\% yang dilakukan dengan tabulasi silang (cross tab) dalam statistik deskriptif. Adanya hubungan antara pemberian imunisasi BCG dengan kejadian tuberkulosis paru pada anak balita. Hal ini ditunjukkan dengan nilai $\mathrm{OR}=$ $0,804 \quad(<1)$ pada variabel pemberian imunisasi BCG dengan interval kepercayaan batas bawah 0,043 dan batas atas 5,586 .

Tabel 1. Karakteristik responden berdasarkan usia di Puskesmas Tuminting

\begin{tabular}{crrrrrc}
\hline \multirow{2}{*}{ Umur } & \multicolumn{2}{c}{ Kasus } & \multicolumn{2}{c}{ Kontrol } & & Total \\
& $\mathrm{N}$ & $\%$ & $\mathrm{~N}$ & $\%$ & $\mathrm{~N}$ & $\%$ \\
\hline$<3$ tahun & 10 & 17,85 & 11 & 19,64 & 21 & 37,5 \\
$>3$ tahun & 15 & 26,78 & 20 & 35,71 & 35 & 62,5 \\
\hline
\end{tabular}

Tabel 2. Karakteristik Respon Berdasarkan Jenis Kelamin di Puskesmas Tuminting

\begin{tabular}{lcccccc}
\hline \multicolumn{1}{c}{ Jenis } & \multicolumn{2}{c}{ Kasus } & \multicolumn{2}{c}{ Kontrol } & \multicolumn{2}{c}{ Total } \\
kelamin & $\mathrm{N}$ & $\%$ & $\mathrm{~N}$ & $\%$ & $\mathrm{~N}$ & $\%$ \\
\hline Perempuan & 8 & 15,28 & 15 & 26,78 & 23 & 41,08 \\
Laki-laki & 17 & 30,25 & 16 & 28,57 & 33 & 58,92 \\
\hline
\end{tabular}

Tabel 3. Kejadian Tuberkulosis Paru di Puskesmas Tuminting

\begin{tabular}{lcc}
\hline $\begin{array}{c}\text { Kejadian Tuberkulosis } \\
\text { Paru }\end{array}$ & N & $\begin{array}{c}\text { Persentase } \\
(\%)\end{array}$ \\
\hline Tuberkulosis Paru & 25 & 45,65 \\
Tidak Tuberkulosis Paru & 31 & 55,35 \\
Total & 56 & 100 \\
\hline
\end{tabular}


Susanto, Wahani, Rompis: Hubungan pemberian BCG dengan kejadian ...

Tabel 4. Hasil Analisis Bivariat Hubungan Pemberian Imunisasi BCG dengan kejadian Tuberkulosis Paru

\begin{tabular}{lccccccc}
\hline $\begin{array}{l}\text { Pemberian Imunisasi } \\
\text { BCG }\end{array}$ & Kasus & & Kontrol & Total & OR \\
& $\mathrm{N}$ & \multicolumn{1}{c}{$\%$} & $\mathrm{~N}$ & $\%$ & $\mathrm{~N}$ & $\%$ & \\
& 23 & 3,36 & 30 & 56,60 & 53 & 100 & 0,804 \\
Imunisasi BCG & 2 & 66,66 & 1 & 33,33 & 3 & 100 & \\
Tidak Imunisasi BCG & 25 & 44,65 & 31 & 55,35 & 56 & 100 & \\
Total & & & & & & &
\end{tabular}

\section{BAHASAN}

Berdasarkan hasil penelitian bahwa sebagian besar responden mendapatkan imunisasi BCG yaitu sebanyak 53 responden (94,64\%). Pemberian imunisasi BCG merupakan bagian dari faktor imunisasi yang dianalisis untuk memrediksi kejadian TB paru pada anak. Pemberian imunisasi BCG dapat melindungi anak dari meningitis TB dan TB milier dengan derajad proteksi sekitar 86\%. Hal ini menimbulkan hipotesis bahwa BCG melindungi terhadap penyebaran bakteri secara hematogen, tetapi tidak mampu membatasi pertumbuhan fokus yang terlokalisasi seperti pada TB paru. ${ }^{13}$

Berdasarkan penelitian yang dilakukan, ditemukan 25 responden yang menderita TB paru. TB paru merupakan penyakit menular langsung yang disebabkan oleh Mycobacterium tuberculosis yang menyerang paru. ${ }^{14}$ Kuman ini berbentuk batang mempunyai sifat khusus yaitu tahan terhadap asam pada pewarnaan (Basil Tahan Asam, BTA). Penderita TB BTA positif sebagai perantara penyebaran kuman ke udara dalam bentuk droplet (percikan darah) pada waktu batuk dan bersin. $^{12}$ TB pada anak didasarkan atas gambaran klinis, gambaran foto rontgen dada dan uji tuberkulosis sehingga harus memperhatikan hal-hal yang mempunyai riwayat berkaitan erat dengan penderita $\mathrm{TB}$ BTA positif, tes tuberkulosis yang positif $(>10 \mathrm{~mm})$. Gambaran foto rontgen sugestif TB dan terdapat reaksi kemerahan lebih cepat (dalam 3-7 hari) setelah imunisasi BCG. Batuk lebih dari 3 minggu, sakit dan demam lama atau berulang tanpa sebab yang jelas, berat badan turun tanpa sebab yang jelas atau tidak naik dalam satu bulan meskipun sudah dengan penanganan gizi yang baik, serta gejala-gejala klinis spesifik (pada kelenjar limfe, otak, tulang dan lainlain). ${ }^{12}$

Pemberian imunisasi BCG merupakan bagian dari faktor imunisasi yang dianalisis untuk mencegah kejadian tuberkulosis paru anak. Dari hasil analisis diketahui ada 23 kasus yang mendapat imunisasi BCG terkena TB paru dan 30 kasus yang mendapat imunisasi BCG tetapi tidak terkena TB paru. Secara statistik variabel tersebut menunjukkan adanya hubungan antara imunisasi BCG dan kejadian TB paru. Pada analisis bivariat didapatkan Rasio Odds (RO) dengan interval kepercayaan (CI) 95\% sebesar 0,804 yang berarti anak yang mendapatkan imunisasi BCG memiliki kemungkinan terkena TB paru 0,804 kali. Hasil penelitian ini sejalan dengan penemuan Briassoulis (2005) bahwa imunisasi BCG tidak sepenuhnya melindungi anak dari serangan tuberkulosis paru, juga teori Utama (2003) bahwa tingkat efektivitas vaksin BCG 0-80\% bisa melindungi sebagian besar rakyat dari kuman tuberkulosis.

Penelitian Pizzo dan Wilfert (1994) melaporkan bahwa sel-sel imunokompeten tubuh telah terbentuk sempurna pada waktu bayi lahir. Pemberian vaksinasi BCG lebih dini akan menimbulkan respon imun yang lebih dini pula, terutama respon imun seluler bukan respon imun humoral. Karena respon imun berkaitan erat dengan kemampuan tubuh untuk melawan penyakit maka hasil penelitian yang dilakukan penulis memberikan indikasi bahwa pemberian imunisasi akan menumbuhkan daya tahan tubuh terhadap penyakit tuberkulosis dengan demikian dapat 
mencegah tuberkulosis paru lebih awal. ${ }^{14}$

Pada penelitian yang dilakukan, anak balita yang menderita tuberkulosis paru sebagian besar sudah mendapat imunisasi BCG karena kebijakkan Departemen Kesehatan RI pada tahun 2002 bahwa anak yang lahir di rumah sakit dan fasilitas kesehatan yang memadai imunisasi BCG diberikan segera setelah lahir. ${ }^{8}$ Anak balita yang tidak imunisasi BCG diperoleh dari anak yang bertempat tinggal jauh dari fasilitas kesehatan yang memadai dan orang tua lupa atau tidak mengetahui informasi tentang imunisasi BCG terhadap anaknya yang seharusnya diberikan imunisasi BCG dalam masa inkubasi (setelah lahir atau sampai umur 2 bulan). Anak yang telah diberikan imunisasi BCG dapat ditemukan adanya jaringan parut (scar) pada lengan kanan.

Berdasarkan hasil analisis bivariat ternyata anak balita yang mendapatkan imunisasi BCG ditemukan ada hubungan atau asosiasi dengan kejadian tuberkulosis paru pada anak.

\section{SIMPULAN}

Berdasarkan hasil penelitian dan bahasan dapat disimpulkan bahwa:

1. Sebagian besar anak balita yang berobat di Puskesmas Tuminting telah diberikan imunisasi BCG.

2. Kejadian tuberkulosis pada anak di Puskesmas Tuminting sebagian besar ditemukan pada umur $>3$ tahun.

3. Terdapat hubungan bermakna antara pemberian imunisasi BCG dengan kejadian tuberkulosis paru pada anak.

\section{DAFTAR PUSTAKA}

1. Newton SM, Brent AJ, Anderson S, Whittaker E, Kampmann B. Paediatric Tuberculosis. Lancet Infect Dis. 2008;8:498-510.

2. Nelson LJ, Wells CD. Global epidemiology of childhood Tuberculosis. Int J Tuberc Lung Dis. 2004;8:636-47.

3. Marais BJ, Obihara CC, Warren RM, Schaaf HS, Gie RP, Donald PR. The burden of childhood Tuberculosis: a public health perspective. Int $\mathrm{J}$ Tuberc Lung Dis. 2005;9:1305-13.

4. Marais BJ. Childhood Tuberculosis: epidemiology and natural history of disease. Indian J Pediatr. 2011;78:321-7.

5. Marais BJ, Gie RP, Hesseling AC, Schaaf HS, Lombard C, Enarson DA, et al. A refined symptom-based approach to diagnose pulmonary Tuberculosis in children. Pediatrics 2006;118:e1350-59.

6. Starke J. Childhood Tuberculosis: Modern View on an Ancient Disease. Texas Children's Hospital. Baylor College of Medicine. 2010. Available from: http://pediatrics.duke.edu/wysiwyg/d ownloads/Childhood_Tuberculosis.pd f, 11 April 2010.

7. WHO Report. Global Tuberculosis control. Epidemiology, strategy, financing. Geneva: World Health Organization, 2009.

8. Departemen Kesehatan RI. Laporan Riskesdas 2009. Jakarta: Badan Penelitian dan Pengembangan Kesehatan Departemen Kesehatan, 2010.

9. Belay M, Bjune G, Ameni G, Abebe M. Serodiagnostic Performance of Resat6-CFP-10 in the Diagnosis of Pulmonary Tuberculosis in Ethiopia. 2011. Avalilable from: http://dx.doi.org/10.4172/2 1611068.1000103.pdf (cited 25 April 2013)

10. WHO. 2007. Immunization. USA, WHO Media Centre. Avalilable from: http://www.who.int/immunization/en/ (cited tanggal 20 November 2012).

11. Dinas Kesehatan provinsi Sulawesi Utara. Profil kesehatan Sulawesi Utara. Manado, 2011.

12. Sri Lanka Medical Association (2011) Guidelines and informationon vaccines (4th ed). Colombo: Sri Lanka Medical Association, 2011.

13. Child Health Developmental Record. Ministry of Health \& nutrition Sri Lanka. Colombo: UNICEF, 2013.

14. Sofiudin. 2009. [cited 9 April 2010]. TBC Pada Anak. Available from: http://one.indoskripsi.com/node/9743. 